Abstracta Iranica Abstracta Iranica

Revue bibliographique pour le domaine irano-aryen

Volume 25 | 2004

Comptes rendus des publications de 2002

\title{
L'Azerbaïdjan. Paris, Karthala, 2002, 390 p., cartes, ill., [24] photos n. \& b.
}

\section{Bayram Balci}

\section{(2) OpenEdition}

1 Journals

\section{Édition électronique}

URL : http://journals.openedition.org/abstractairanica/4052

DOI : 10.4000/abstractairanica.4052

ISSN : 1961-960X

Éditeur :

CNRS (UMR 7528 Mondes iraniens et indiens), Éditions de l'IFRI

\section{Édition imprimée}

Date de publication : 15 mai 2004

ISSN : 0240-8910

\section{Référence électronique}

Bayram Balci, «L'Azerbaïdjan. Paris, Karthala, 2002, 390 p., cartes, ill., [24] photos n. \& b. », Abstracta Iranica [En ligne], Volume 25 | 2004, document 16, mis en ligne le 15 mars 2006, consulté le 25

septembre 2020. URL : http://journals.openedition.org/abstractairanica/4052 ; DOI : https://doi.org/ 10.4000/abstractairanica.4052

Ce document a été généré automatiquement le 25 septembre 2020.

Tous droits réservés 


\title{
L'Azerbaïdjan. Paris, Karthala, 2002, 390 p., cartes, ill., [24] photos n. \& b.
}

\author{
Bayram Balci
}

1 Le grand mérite de l'A. est de mettre à la disposition du lecteur francophone un réel manuel sur l'Azerbaïdjan contemporain. En effet il n'existe pas d'autre ouvrage de ce genre, en français, sur cette jeune république ex-soviétique. Par sa richesse d'informations, contemporaines mais surtout historiques, le livre s'impose comme une alternative possible à l'ouvrage de référence d'Audrey L. Altstadt, The Azerbaijani Turks. Power and Identity under Russian Rule (Stanford, Hoover Institution Press, 1992).

2 L'ouvrage est composé de treize chapitres. Les cinq premiers, organisés selon les principales étapes de l'histoire du pays, offrent un survol géographique et historique : le volet « albanais », les périodes du califat et des Seldjoukides, l'épisode des Atabegs et des clans turcomans, et la rivalité turco-persane pour le contrôle de l'actuel Azerbaïdjan. Les chapitres six, sept et huit sont consacrés, pour l'essentiel, à la conquête russe à l'instauration d'un ordre russe. L'A. ne se contente pas de relater l'histoire de la colonisation, mais se livre également à une analyse des mutations internes de la société azerbaïdjanaise ; la littérature et les courants intellectuels sont également étudiés en détail, pour permettre au lecteur de mieux comprendre le « réveil national » qui interviendra à la fin de la période soviétique. Le lecteur néophyte se surprendra à constater, aussi, combien la modernisation politique et institutionnelle opérée en Turquie par Mustapha Kemal s'est inspiré de ce qui avait été pensé et réalisé en Azerbaïdjan depuis le début du $20^{\mathrm{e}} \mathrm{s}$. Les débats de cette période sur la réforme de l'alphabet, le statut de la femme, la modernisation du système judiciaire sont ainsi bien mis en évidence.

Les trois chapitres suivants sont consacrés, eux, à la situation de l'Azerbaïdj an entre la Première Guerre mondiale, laquelle annonce l'incorporation du pays dans l'URSS (avec une bonne analyse de la courte période de la première indépendance, entre 1918 et 1920), puis à la soviétisation et aux purges dans années 1930, enfin à la « stagnation » et à la perestroïka. Les deux derniers chapitres étudient l'Azerbaïdjan indépendant, avec une nette focalisation sur le conflit avec l'Arménie et les tensions politiques à 
l'intérieur du pays. Les différentes forces politiques en présence sont présentées de manière claire, même si l'A. semble avoir complètement négligé le champ religieux pourtant fort significatif dans la nouvelle société azerbaïdjanaise. En effet, très peu d'analyses sont consacrées à l'islam, sous sa forme chiite majoritaire ou sunnite minoritaire. Cette lacune est sans doute le principal reproche qu'on peut faire à l'A., en plus d'une cartographie déplorable; imprécises, les cartes établies par le ministère français des Affaires Étrangères qu'utilise l'A., n'apportent pas l'éclaircissement escompté à un texte d'une grande richesse analytique.

INDEX

Thèmes : 1.3. Ouvrages généraux, histoire de la discipline

\section{AUTEURS}

BAYRAM BALCI

IFEA - Istanbul 